\title{
Ranking Economics and Econometrics ISI Journals by Quality Weighted Citations*
}

\author{
Chia-Lin Chang \\ Department of Applied Economics \\ Department of Finance \\ National Chung Hsing University \\ Taiwan
}

\author{
Michael McAleer \\ Department of Quantitative Finance \\ National Tsing Hua University \\ Taiwan \\ and \\ Econometric Institute \\ Erasmus School of Economics \\ Erasmus University Rotterdam \\ and \\ Tinbergen Institute \\ The Netherlands \\ and \\ Department of Quantitative Economics \\ Complutense University of Madrid
}

February 2014

* The authors are grateful to Essie Maasoumi for helpful discussions. For financial support, the first author wishes to thank the National Science Council, Taiwan, and the second author acknowledges the Australian Research Council and the National Science Council, Taiwan. 


\begin{abstract}
The paper analyses academic journal quality and impact using quality weighted citations that are based on the widely-used Thomson Reuters ISI Web of Science citations database (ISI). A recently developed Index of Citations Quality (ICQ), based on quality weighted citations, is used to analyse the top 276 Economics and top 10 Econometrics journals in the ISI Economics category using alternative quantifiable Research Assessment Measures (RAMs). It is shown that ICQ is a useful additional measure to the 2-Year Impact Factor (2YIF) and other well known RAMs available in ISI for the purpose of evaluating journal impact and quality, as well as ranking, of Economics and Econometrics journals as it contains information that has very low correlations with the information contained in alternative wellknown RAMs. Among other findings, the top Econometrics journals have some of the highest ICQ scores in the ISI category of Economics.
\end{abstract}

Keywords: Research assessment measures, Impact factors, Eigenfactor, Article Influence, Quality weighted citations, Index of citations quality, Economics journal rankings.

JEL Classifications: C18, C81, Y10. 


\section{Introduction}

It is widely accepted that an objective assessment of the quality, impact and influence of academic journals should be based on quantifiable bibliometric Research Assessment Measures (RAMs). Most well-known and influential RAMs are based on alternative transformations of citations data. The citations data may be based on total citations or they may be weighted by quality, as defined according to some quantifiable measure.

One of the leading databases for generating RAMs to evaluate research performance and quality is the Thomson Reuters ISI Web of Science (2013) database (hereafter ISI). It would be safe to state that ISI is the benchmark against which other databases, such as SciVerse Scopus, Google Scholar and Microsoft Academic Search, are compared. Although there are important and widely-accepted caveats regarding the methodology and data collection methods underlying any citations database, including ISI, the ISI citations database is certainly one of the most widely-accessed sources of citations-based RAMs.

The use of any RAM based on citations data presumes that journals would prefer to have a higher number of citations, and hence greater impact and influence, in general. In this context, the most well known citations measures are the ISI 2-year impact factor (2YIF) and 5-year impact factor (5YIF). However, both of these RAMs include journal self citations. Self citations do not necessarily reflect any bias in citations-based RAMs, but it may reasonably be argued that some, if not many, journals self inflate the number of citations through coercive practices.

Chang and McAleer (2014) and Chang et al. (2011, 2014), among others, have argued that disproportionate journal self citations, which may arise from the editorial practices of journals or through pressure from the publishers of journals, can inflate and distort the impact factor of a journal. The latter type of journal self citation is widely regarded as coercive behaviour, and hence is unprofessional.

New RAMs have been developed in recent years to try to reduce the effects of coercive journal self citations. For example, impact factors that exclude journal self citations can be constructed, although this has the effect of reducing impact factors, which is generally unappealing to editors and publishers of journals. RAMs that exclude journal self citations 
include the Eigenfactor and Article Influence scores, which will be discussed in the next section. It is widely accepted that journal editors, publishers and publishing authors would prefer to have higher Eigenfactor and Article Influence scores, in general, than lower.

The paper follows closely the outline of Chang and McAleer (2014), who suggested a new RAM, namely an Index of Citations Quality (ICQ) that is based on quality weighted citations data. They also applied their new measure to the top 500 journals, selected on the basis of the 2-year impact factor (2YIF), in each of the Sciences and Social Sciences.

In this paper it is shown that ICQ is a useful additional measure to 2YIF and other well known RAMs available in ISI for the purpose of evaluating journal impact and quality, as well as ranking, of Economics and Econometrics journals as it contributes information that has a very low correlation with the information contained in alternative well-known RAMs. Among other findings, the top Econometrics journals have some of the highest ICQ scores in the ISI category of Economics.

The plan of the remainder of the paper is as follows. In Section 2, alternative Research Assessment Measures (RAMs) for total citations and quality weighted citations are discussed. In Section 3, the recently developed Index of Citations Quality (ICQ) is discussed. Section 4 presents an analysis of rankings based on quality weighted citations for the top 276 economics journals and the top 10 econometrics journals in the ISI Economics category. Some concluding remarks are given in Section 5.

\section{RAMs for Total Citations and Quality Weighted Citations}

The Thomson Reuters ISI Web of Science (2013) is perhaps the most widely-used citations database for evaluating journal impact and quality. As discussed in, for example, Chang and McAleer (2013, 2014), Chang, Maasoumi and McAleer 92014), and Chang, McAleer and Oxley (2011a, b, c), among others, the RAMs are intended as descriptive statistics to capture journal impact and performance, and are not based on a theoretical model. These authors have emphasized that there is no optimization or estimation required to calculate the alternative RAMs that are based on citations data. With two exceptions, namely Eigenfactor 
and Article Influence, existing RAMs are reported separately for the Sciences and Social Sciences.

The definitions and descriptions of the RAMs discussed in this paper have been analysed critically in, for example, Chang and McAleer (2013, 2014) and Chang, Maasoumi and McAleer (2014). The annual RAMs given below are calculated for a Journal Citations Reports (JCR) calendar year, which is the year before the annual RAMs are released. For example, the RAMs were released in late-June 2013 for the JCR calendar year 2012.

As the definitions of the RAMs that are used in this paper may not be widely known, they are reproduced below to facilitate ease of presentation. Although 2YIF is not required for purposes of calculating the new Index of Citations Quality (ICQ) of Chang and McAleer (2014), 2YIF is included as it is the most widely-used RAM and also to facilitate comparisons with the rankings based on ICQ.

\section{(1) 2-year impact factor including journal self citations (2YIF):}

The classic 2-year impact factor including journal self citations (2YIF) of a journal is typically referred to as "the impact factor", is calculated annually, and is defined as "Total citations in a year to papers published in a journal in the previous 2 years / Total papers published in a journal in the previous 2 years”. It is widely held in the academic community, and certainly by the editors and publishers of journals, that a higher 2YIF is better than lower.

\section{(2) 5-year impact factor including journal self citations (5YIF):}

The 5-year impact factor including journal self citations (5YIF) of a journal is calculated annually, and is defined as "Total citations in a year to papers published in a journal in the previous 5 years, including journal self citations" / "Total papers published in a journal in the previous 5 years." It is widely held in the academic community that a higher 5YIF is preferred to lower.

\section{(3) Eigenfactor (or Journal Influence):}


The Eigenfactor score (see Bergstrom (2007), Bergstrom and West (2008), Bergstrom, West and Wiseman (2008)) is calculated annually (see www.eigenfactor.org), and is defined as: “The Eigenfactor Score calculation is based on the number of times articles from the journal published in the past five years have been cited in the JCR year, but it also considers which journals have contributed these citations so that highly cited journals will influence the network more than lesser cited journals. References from one article in a journal to another article from the same journal are removed, so that Eigenfactor Scores are not influenced by journal self-citation.” The value of the threshold that separates 'highly cited' from 'lesser cited' journals, as well as how the former might 'influence the network more' than the latter, are based on the Eigenfactor score of the citing journal. Thus, Eigenfactor might usefully be interpreted as a quality weighted citations score, or a "Journal Influence” measure, namely "Total citations, excluding journal self citations, in the previous 5 years, weighted by journal quality” (see Chang, Maasoumi and McAleer (2014)). A higher Eigenfactor score would be preferred to lower.

\section{(4) Article Influence (or Journal Influence per Article):}

Article Influence (see Bergstrom (2007), Bergstrom and West (2008), Bergstrom, West and Wiseman (2008)) measures the relative importance of a journal's citation influence on a perarticle basis. Despite the misleading suggestion of measuring "Article Influence”, as each journal has only a single "Article Influence" score, this RAM is actually a "Journal Influence per Article” score (see Chang, Maasoumi and McAleer (2014)). Article Influence is a scaled Eigenfactor score, is calculated annually, is standardized to have a mean of one across all journals in the Thomson Reuters ISI database, and is defined as "Eigenfactor score divided by the fraction of all articles published by a journal in the previous five years", or equivalently, "Total citations, excluding journal self citations, in the past 5 years, weighted by journal quality, divided by the fraction of all articles published by a journal”. A higher Article Influence would be preferred to lower.

\section{An Index of Citations Quality (ICQ)}


Wilhite and Fong (2012) and Chang, McAleer and Oxley (2013), among others, have argued that the pervasive practice of coercive journal citations by both editors and publishers can and does distort the inherent meaning and interpretation of journal impact and influence. The exclusion of journal self citations is one, though not the only, reason for the development of new RAMs such as Eigenfactor and Article Influence (AI) scores to measure journal impact and influence.

The definitions of the RAMs in the previous section show that a 5-year period is used to calculate 5YIF, Eigenfactor and AI. As 5YIF includes journal self citations and does not weight citations by quality, whereas Eigenfactor and AI exclude journal self citations and use quality weighted citations, it is clear that there are significant differences between 5YIF, on the one hand, and Eigenfactor and AI, on the other.

Chang and McAleer (2014) suggested the following Index of Citations Quality (ICQ) as a new RAM, wherein it is regarded as obvious that a higher ICQ would generally be preferred to lower:

\section{Definition: Index of Citations Quality (ICQ)}

\section{ICQ = AI / 5YIF = Quality Weighted Citations / Total Citations}

= "Quality weighted citations in the past 5 years, excluding journal self citations" / “Total citations in the previous 5 years, including journal self citations"

The next section calculates ICQ for the top 276 Economics journals in the ISI category of Economics, and a subset of the top 10 Econometrics journals, for which there are data on both 5YIF and AI, compares the correlations among 2YIF, 5YIF, Eigenfactor, AI and ICQ, and calculates the correlations between the rankings based on 2YIF and ICQ. Although 2YIF is not used in the calculation of ICQ, 2YIF is nevertheless presented because it is the most widely-used RAM from ISI.

\section{Analysis of Rankings based on Quality Weighted Citations for the Top 276 Economics and Top 10 Econometrics Journals}


For purposes of ranking journals by ICQ, data were downloaded from ISI on 2YIF, 5YIF, Eigenfactor and AI for the 333 journals in the ISI category of Economics. Chang and McAleer (2014) observed that the leading 21 journals, and 24 of the leading 25 journals, of the top 500 journals in the Social Sciences, for which there are 3,047 Journals, were from the Economics category.

The journal acronyms are taken from ISI, and the data were downloaded from ISI on 21 February 2014. As 57 of the 333 journals in Economics do not have data on both 5YIF and AIs, these journals are deleted to obtain the top 276 Economics journals and a subset of the top 10 econometrics journals (see Tables 1 and 2).

The rankings of journals in Tables 1 and 2 are based on ICQ. It is noted from Table 1 for the top 276 Economics journals that the mean ICQ is 0.679, its standard deviation is 0.37, its range is $(0.058,1.772)$, the means of 2 YIF and 5YIF are 1.151 and 1.506 , respectively, and the mean $\mathrm{AI}$ is 1.236 .

Compared with the 2YIF rankings, the largest jump in the rankings according to ICQ is 265, with only one journal increasing its ranking by more than 200 of the possible maximum of 275 positions. The largest drop in rankings from 2YIF to ICQ is 248, with 10 journals dropping by more than 200 positions. It is clear that rankings according to ICQ and 2YIF lead to very different outcomes.

In comparison with Economics, it can be seen from Table 2 for the top 10 Econometrics journals that the mean ICQ is much higher at 1.255, its standard deviation is lower at 0.262 , its range is much smaller at $(0.862,1.687)$, the mean 2YIF and mean 5YIF are much higher at 1.665 and 2.437, respectively, and the mean AI is considerably higher at 3.162, arising primarily from the highest ranked journal.

In Table 2, the ICQ are ranked according to the cohort of the top 10 Econometrics journals and also by the cohort of the 276 Economics journals. It is clear that the top 10 Econometrics journals fare very well in comparison with the top 276 Economics journals as a whole, with 2 journals in the top 5, 5 in the top 30, 8 in the top 50, and all 10 journals in the top 73 . 
The correlations of ICQ Rank and 2YIF Rank for the 276 Economics and 10 Econometrics journals are given in Tables 3 and 5, respectively. The correlation of the rankings based on ICQ and 2YIF for Economics is 0.302 and for Econometrics it is 0.338. Bearing in mind that the numbers of journals are very different at 276 and 10, respectively, for Economics and Econometrics, the correlations are similar and also quite low. As was shown in Chang and McAleer (2014) for the top 500 journals chosen on the basis of 2YIF in both the Sciences and Social Sciences, ICQ is a useful additional RAM to 2YIF for the purpose of ranking journals as it contributes information that has a very low correlation with the information that is contained in 2YIF.

The correlations of 2YIF, 5YIF, Eigenfactor, AI and ICQ are given in Tables 4 and 6 for Economics and Econometrics, respectively. The highest correlations in both tables are between 2YIF and 5YIF, at virtually identical values of 0.952 and 0.957 for Economics and Econometrics, respectively. The correlations of AI with each of 2YIF and 5YIF are very high at 0.949 and 0.955 , respectively, for Econometrics, but the corresponding correlations for Economics are slightly lower at 0.808 and 0.883 , respectively. The correlations of ICQ with 2YIF, 5YIF and Eigenfactor for Economics are 0.373, 0.426 and 0.487, respectively, and the corresponding correlations for Econometrics are 0.464, 0.301 and 0.391, respectively, all of which are relatively low. The correlations of ICQ and AI are higher at 0.676 and 0.543 for Economics and Econometrics, respectively.

Overall, as in Chang and McAleer (2014) for the top 500 journals chosen on the basis of 2YIF in both the Sciences and Social Sciences, the low correlations of the 2YIF Ranks and ICQ Ranks, and the relatively low correlations of ICQ with each of 2YIF, 5YIF, Eigenfactor and AI, suggest that ICQ is a useful additional RAM for purposes of evaluating and ranking the impact and quality of the leading journals in Economics and Econometrics.

\section{Concluding Remarks}

The paper evaluated the ranking of academic journal quality and impact using the Thomson Reuters ISI Web of Science (2013) citations database (hereafter ISI) for the top 276 Economics and top 10 Econometrics journals which had data on both Article Influence (AI) 
and 5YIF. The journals were chosen from the ISI Economics category, and were ranked according to the recently developed RAM, namely the Index of Citations Quality (ICQ).

There were considerable differences between the alternative RAMs for Economics and Econometrics, with the impact factors and AI scores being much higher, on average, for the top 10 Econometrics journals than for the top 276 Economics journals. The ICQ scores were also higher, on average, for the Econometrics journals than for their Economics counterparts.

It was shown that ICQ is a useful addition to 2YIF and other well known RAMs for the purpose of evaluating the impact and quality, as well as ranking, of journals as it contributes information that has a very low correlation with the information that is contained in 2YIF and other well known RAMs for both Economics and Econometrics.

Chang and McAleer (2014) showed that, of the leading journals in the Social Sciences selected on the basis of 2YIF, the journals with the highest ICQ were generally from the Economics category. This paper has shown that a similar comment would also seem to apply to the top Econometrics journals in the ISI category of Economics. 


\section{References}

Bergstrom C. (2007), Eigenfactor: Measuring the value and prestige of scholarly journals, C\&RL News, 68, 314-316.

Bergstrom, C.T. and. J.D. West (2008), Assessing citations with the Eigenfactor ${ }^{\mathrm{TM}}$ metrics, Neurology, 71, 1850-1851.

Bergstrom, C.T., J.D. West and M.A. Wiseman (2008), The Eigenfactor ${ }^{\mathrm{TM}}$ metrics, Journal of Neuroscience, 28(45), 11433-11434 (November 5, 2008).

Chang, C.-L. and M. McAleer (2013), Ranking leading econometrics journals using citations data from ISI and RePEc, Econometrics, 1(3), 217-235.

Chang, C.-L. and M. McAleer (2014), Quality weighted citations versus total citations in the sciences and social sciences, Tinbergen Institute Discussion Paper 14-023/III, Tinbergen Institute, The Netherlands.

Chang, C.-L., E. Maasoumi and M. McAleer (2014), Robust ranking of journal quality: An application to economics, to appear in Econometric Reviews.

Chang, C.-L., M. McAleer and L. Oxley (2011a), Great expectatrics: Great papers, great journals, great econometrics, Econometric Reviews, 30(6), 583-619.

Chang, C.-L., M. McAleer and L. Oxley (2011b), What makes a great journal great in economics? The singer not the song, Journal of Economic Surveys, 25(2), 326-361.

Chang, C.-L., M. McAleer and L. Oxley (2011c), What makes a great journal great in the sciences? Which came first, the chicken or the egg?, Scientometrics, 87(1), 17-40.

Chang, C.-L., M. McAleer and L. Oxley (2013), Coercive journal self citations, impact factor, journal influence and article influence, Mathematics and Computers in Simulation, 93, 190-197.

ISI Web of Science (2014), Journal Citation Reports, Essential Science Indicators, Thomson Reuters ISI.

Wilhite, A.W. and E.A. Fong (2012), Coercive citation in academic publishing, Science, 335 (6068), 542-543. 
Table 1. Top 276 Economics Journals Ranked by ICQ

\begin{tabular}{|c|c|c|c|c|c|c|c|}
\hline Journal Title & ICQ Rank & 2YIF Rank & ICQ & $2 \mathrm{YIF}$ & 5YIF & Eigenfactor & AI \\
\hline ANNU REV FINANC ECON & 1 & 173 & 1.772 & 0.694 & 0.627 & 0.00099 & 1.111 \\
\hline REV ECON STUD & 2 & 18 & 1.748 & 2.86 & 4.111 & 0.03063 & 7.188 \\
\hline REV ECON DYNAM & 3 & 68 & 1.71 & 1.602 & 1.625 & 0.00971 & 2.779 \\
\hline ECONOMETRICA & 4 & 5 & 1.687 & 3.823 & 5.702 & 0.04571 & 9.622 \\
\hline ECONOMET THEOR & 5 & 77 & 1.683 & 1.477 & 1.473 & 0.01273 & 2.479 \\
\hline AM ECON J-MACROECON & 6 & 15 & 1.682 & 3.191 & 4.092 & 0.01046 & 6.882 \\
\hline J POLIT ECON & 7 & 9 & 1.675 & 3.483 & 5.506 & 0.0248 & 9.222 \\
\hline IMF ECON REV & 8 & 25 & 1.63 & 2.529 & 2.559 & 0.00248 & 4.172 \\
\hline AM ECON J-MICROECON & 9 & 51 & 1.586 & 1.884 & 1.978 & 0.00488 & 3.138 \\
\hline ECON CHIL & 10 & 275 & 1.576 & 0.031 & 0.033 & 0.00008 & 0.052 \\
\hline J ECON THEORY & 11 & 113 & 1.523 & 1.069 & 1.522 & 0.0253 & 2.318 \\
\hline Q J ECON & 12 & 2 & 1.498 & 5.278 & 8.147 & 0.04647 & 12.205 \\
\hline J MONETARY ECON & 13 & 63 & 1.48 & 1.649 & 2.529 & 0.02718 & 3.742 \\
\hline AM ECON J-APPL ECON & 14 & 7 & 1.443 & 3.539 & 3.836 & 0.01064 & 5.537 \\
\hline ANNU REV ECON & 15 & 80 & 1.443 & 1.44 & 2.268 & 0.00406 & 3.273 \\
\hline RAND J ECON & 16 & 78 & 1.429 & 1.47 & 2.095 & 0.01103 & 2.994 \\
\hline J FINANC & 17 & 3 & 1.427 & 4.333 & 6.185 & 0.05733 & 8.824 \\
\hline BE J THEOR ECON & 18 & 217 & 1.416 & 0.419 & 0.442 & 0.00216 & 0.626 \\
\hline ECONOMET J & 19 & 120 & 1.372 & 1 & 1.252 & 0.00417 & 1.718 \\
\hline AM ECON REV & 20 & 20 & 1.358 & 2.792 & 4.16 & 0.10035 & 5.65 \\
\hline REV FINANC STUD & 21 & 13 & 1.349 & 3.256 & 5.367 & 0.06476 & 7.242 \\
\hline INT ECON REV & 22 & 103 & 1.332 & 1.162 & 1.922 & 0.01096 & 2.561 \\
\hline AM ECON J-ECON POLIC & 23 & 44 & 1.316 & 2 & 2.304 & 0.00418 & 3.032 \\
\hline ECONOMET REV & 24 & 147 & 1.316 & 0.811 & 1.321 & 0.00425 & 1.738 \\
\hline BROOKINGS PAP ECO AC & 25 & 6 & 1.292 & 3.68 & 5.556 & 0.0079 & 7.181 \\
\hline
\end{tabular}




\begin{tabular}{|c|c|c|c|c|c|c|c|}
\hline Journal Title & ICQ Rank & 2YIF Rank & ICQ & 2YIF & 5YIF & Eigenfactor & $\mathrm{AI}$ \\
\hline J LABOR ECON & 26 & 60 & 1.259 & 1.729 & 3.009 & 0.00747 & 3.787 \\
\hline J BUS ECON STAT & 27 & 48 & 1.254 & 1.932 & 2.369 & 0.01027 & 2.97 \\
\hline J FINANC ECON & 28 & 10 & 1.244 & 3.424 & 5.087 & 0.05835 & 6.327 \\
\hline J FINANC QUANT ANAL & 29 & 64 & 1.242 & 1.636 & 2.13 & 0.01169 & 2.645 \\
\hline GAME ECON BEHAV & 30 & 121 & 1.229 & 1 & 1.356 & 0.01619 & 1.667 \\
\hline J IND ECON & 31 & 101 & 1.202 & 1.194 & 1.539 & 0.0054 & 1.85 \\
\hline J ECONOMETRICS & 32 & 61 & 1.199 & 1.71 & 2.713 & 0.04063 & 3.254 \\
\hline QME-QUANT MARK ECON & 33 & 92 & 1.164 & 1.276 & 1.77 & 0.00266 & 2.06 \\
\hline J EUR ECON ASSOC & 34 & 42 & 1.159 & 2.049 & 2.49 & 0.01472 & 2.887 \\
\hline INT J GAME THEORY & 35 & 188 & 1.154 & 0.584 & 0.609 & 0.00264 & 0.703 \\
\hline REV ECON STAT & 36 & 28 & 1.153 & 2.346 & 3.669 & 0.02639 & 4.232 \\
\hline J ECON PERSPECT & 37 & 8 & 1.143 & 3.489 & 5.864 & 0.02587 & 6.703 \\
\hline J MATH ECON & 38 & 232 & 1.104 & 0.321 & 0.454 & 0.00351 & 0.501 \\
\hline J FINANC ECONOMET & 39 & 126 & 1.091 & 0.976 & 1.58 & 0.00301 & 1.724 \\
\hline IMF STAFF PAPERS & 40 & 29 & 1.082 & 2.312 & 1.344 & 0.00244 & 1.454 \\
\hline ASIAN ECON POLICY R & 41 & 238 & 1.052 & 0.28 & 0.629 & 0.00072 & 0.662 \\
\hline FED RESERVE BANK ST & 42 & 180 & 1.051 & 0.64 & 0.748 & 0.00185 & 0.786 \\
\hline J ECON LIT & 43 & 1 & 1.046 & 6.667 & 10.16 & 0.01745 & 10.628 \\
\hline J PUBLIC ECON THEORY & 44 & 201 & 1.031 & 0.494 & 0.511 & 0.00212 & 0.527 \\
\hline J HUM RESOUR & 45 & 45 & 1.03 & 1.985 & 3.132 & 0.00941 & 3.226 \\
\hline J LAW ECON ORGAN & 46 & 131 & 1.018 & 0.932 & 1.932 & 0.00402 & 1.967 \\
\hline MATH FINANC & 47 & 122 & 1.016 & 1 & 1.463 & 0.00382 & 1.486 \\
\hline BE J ECON ANAL POLI & 48 & 194 & 1.011 & 0.551 & 0.76 & 0.00552 & 0.768 \\
\hline ECON POLICY & 49 & 22 & 1.004 & 2.688 & 3.013 & 0.00423 & 3.025 \\
\hline ECON THEOR & 50 & 108 & 1.001 & 1.095 & 1.063 & 0.0091 & 1.064 \\
\hline
\end{tabular}




\begin{tabular}{|c|c|c|c|c|c|c|c|}
\hline Journal Title & ICQ Rank & 2YIF Rank & ICQ & 2YIF & 5YIF & Eigenfactor & AI \\
\hline J INT ECON & 51 & 40 & 0.995 & 2.086 & 3.27 & 0.01956 & 3.255 \\
\hline J LAW ECON & 52 & 145 & 0.995 & 0.828 & 1.73 & 0.00457 & 1.721 \\
\hline J MONEY CREDIT BANK & 53 & 107 & 0.995 & 1.104 & 1.7 & 0.0127 & 1.691 \\
\hline EUR J HIST ECON THOU & 54 & 252 & 0.989 & 0.227 & 0.276 & 0.00069 & 0.273 \\
\hline ECON J & 55 & 38 & 0.988 & 2.118 & 3.095 & 0.02296 & 3.057 \\
\hline J ECON HIST & 56 & 154 & 0.982 & 0.766 & 1.096 & 0.00312 & 1.076 \\
\hline SOC CHOICE WELFARE & 57 & 203 & 0.979 & 0.485 & 0.711 & 0.00421 & 0.696 \\
\hline BE J MACROECON & 58 & 246 & 0.974 & 0.244 & 0.503 & 0.00162 & 0.49 \\
\hline J PUBLIC ECON & 59 & 74 & 0.967 & 1.52 & 2.197 & 0.02111 & 2.124 \\
\hline EXP ECON & 60 & 41 & 0.961 & 2.069 & 3.853 & 0.00879 & 3.701 \\
\hline J ECON GROWTH & 61 & 32 & 0.941 & 2.25 & 3.85 & 0.0038 & 3.622 \\
\hline J ECON MANAGE STRAT & 62 & 137 & 0.940 & 0.878 & 1.709 & 0.00511 & 1.607 \\
\hline J APPL ECONOMET & 63 & 53 & 0.934 & 1.867 & 2.521 & 0.00995 & 2.355 \\
\hline ECON HIST REV & 64 & 117 & 0.925 & 1.045 & 1.073 & 0.00307 & 0.993 \\
\hline MACROECON DYN & 65 & 216 & 0.921 & 0.42 & 0.609 & 0.00228 & 0.561 \\
\hline SCAND J ECON & 66 & 178 & 0.915 & 0.645 & 1.249 & 0.00377 & 1.143 \\
\hline ECON INQ & 67 & 110 & 0.886 & 1.09 & 1.31 & 0.00614 & 1.161 \\
\hline HIST POLIT ECON & 68 & 253 & 0.883 & 0.227 & 0.266 & 0.00088 & 0.235 \\
\hline INT J IND ORGAN & 69 & 133 & 0.883 & 0.914 & 1.325 & 0.00748 & 1.17 \\
\hline THEOR DECIS & 70 & 158 & 0.876 & 0.762 & 0.735 & 0.00246 & 0.644 \\
\hline MATH SOC SCI & 71 & 211 & 0.867 & 0.452 & 0.497 & 0.00215 & 0.431 \\
\hline ECON DEV CULT CHANGE & 72 & 130 & 0.862 & 0.943 & 1.357 & 0.00264 & 1.17 \\
\hline OXFORD B ECON STAT & 73 & 170 & 0.862 & 0.707 & 1.767 & 0.00503 & 1.523 \\
\hline ECONOMICA & 74 & 100 & 0.839 & 1.194 & 1.526 & 0.00438 & 1.28 \\
\hline ECON LETT & 75 & 200 & 0.839 & 0.509 & 0.682 & 0.01566 & 0.572 \\
\hline
\end{tabular}




\begin{tabular}{|c|c|c|c|c|c|c|c|}
\hline Journal Title & ICQ Rank & 2YIF Rank & ICQ & 2YIF & 5YIF & Eigenfactor & $\mathrm{AI}$ \\
\hline EUR REV ECON HIST & 76 & 98 & 0.832 & 1.206 & 1.405 & 0.00161 & 1.169 \\
\hline EUR ECON REV & 77 & 86 & 0.823 & 1.331 & 1.648 & 0.00834 & 1.357 \\
\hline J POLICY ANAL MANAG & 78 & 57 & 0.823 & 1.781 & 2.281 & 0.00548 & 1.878 \\
\hline ANN ECON FINANC & 79 & 239 & 0.821 & 0.278 & 0.363 & 0.00047 & 0.298 \\
\hline J INST THEOR ECON & 80 & 212 & 0.813 & 0.443 & 0.417 & 0.00107 & 0.339 \\
\hline J RISK UNCERTAINTY & 81 & 58 & 0.806 & 1.771 & 2.016 & 0.0036 & 1.625 \\
\hline LABOUR ECON & 82 & 112 & 0.794 & 1.076 & 1.483 & 0.00768 & 1.178 \\
\hline CESIFO ECON STUD & 83 & 192 & 0.792 & 0.561 & 0.75 & 0.00133 & 0.594 \\
\hline GER ECON REV & 84 & 162 & 0.789 & 0.736 & 0.843 & 0.00147 & 0.665 \\
\hline J ECON DYN CONTROL & 85 & 148 & 0.788 & 0.807 & 1.21 & 0.01207 & 0.954 \\
\hline NATL TAX J & 86 & 172 & 0.788 & 0.698 & 0.732 & 0.00211 & 0.577 \\
\hline WORLD BANK ECON REV & 87 & 88 & 0.781 & 1.325 & 2.704 & 0.00398 & 2.111 \\
\hline FISC STUD & 88 & 237 & 0.779 & 0.295 & 0.616 & 0.00083 & 0.48 \\
\hline J DEV ECON & 89 & 27 & 0.767 & 2.353 & 2.92 & 0.01518 & 2.24 \\
\hline REV INCOME WEALTH & 90 & 184 & 0.766 & 0.607 & 1.086 & 0.00272 & 0.832 \\
\hline WORLD BANK RES OBSER & 91 & 43 & 0.749 & 2.045 & 2.314 & 0.00154 & 1.734 \\
\hline OXFORD ECON PAP & 92 & 155 & 0.748 & 0.765 & 1.136 & 0.00273 & 0.85 \\
\hline SOUTH ECON J & 93 & 214 & 0.747 & 0.427 & 0.767 & 0.00292 & 0.573 \\
\hline INT TAX PUBLIC FINAN & 94 & 204 & 0.746 & 0.479 & 0.904 & 0.00209 & 0.674 \\
\hline CAN J ECON & 95 & 179 & 0.744 & 0.642 & 0.878 & 0.00335 & 0.653 \\
\hline J ECON BEHAV ORGAN & 96 & 115 & 0.731 & 1.065 & 1.451 & 0.01421 & 1.061 \\
\hline J POPUL ECON & 97 & 84 & 0.731 & 1.336 & 1.462 & 0.00461 & 1.069 \\
\hline PORT ECON J & 98 & 255 & 0.711 & 0.227 & 0.418 & 0.00029 & 0.297 \\
\hline J JPN INT ECON & 99 & 157 & 0.709 & 0.763 & 0.804 & 0.00137 & 0.57 \\
\hline J ENVIRON ECON MANAG & 100 & 46 & 0.693 & 1.969 & 2.97 & 0.00834 & 2.059 \\
\hline
\end{tabular}




\begin{tabular}{|c|c|c|c|c|c|c|c|}
\hline Journal Title & ICQ Rank & 2YIF Rank & ICQ & 2YIF & 5YIF & Eigenfactor & $\mathrm{AI}$ \\
\hline EXPLOR ECON HIST & 101 & 174 & 0.693 & 0.686 & 0.873 & 0.00167 & 0.605 \\
\hline J URBAN ECON & 102 & 50 & 0.689 & 1.91 & 2.87 & 0.00953 & 1.977 \\
\hline CLIOMETRICA & 103 & 66 & 0.689 & 1.615 & 1.153 & 0.00082 & 0.794 \\
\hline JPN ECON REV & 104 & 268 & 0.689 & 0.143 & 0.305 & 0.00055 & 0.21 \\
\hline J COMP ECON & 105 & 177 & 0.680 & 0.657 & 1.552 & 0.00337 & 1.056 \\
\hline SINGAP ECON REV & 106 & 266 & 0.679 & 0.152 & 0.184 & 0.00033 & 0.125 \\
\hline ASTIN BULL & 107 & 171 & 0.678 & 0.698 & 0.898 & 0.00156 & 0.609 \\
\hline PAC ECON REV & 108 & 167 & 0.676 & 0.722 & 0.645 & 0.00152 & 0.436 \\
\hline PUBLIC CHOICE & 109 & 138 & 0.672 & 0.878 & 1.255 & 0.00813 & 0.843 \\
\hline SCOT J POLIT ECON & 110 & 225 & 0.668 & 0.367 & 0.575 & 0.00107 & 0.384 \\
\hline REG SCI URBAN ECON & 111 & 97 & 0.666 & 1.228 & 1.628 & 0.00473 & 1.084 \\
\hline QUANT FINANC & 112 & 146 & 0.661 & 0.824 & 0.957 & 0.0046 & 0.633 \\
\hline INT J FORECASTING & 113 & 81 & 0.654 & 1.424 & 1.779 & 0.00551 & 1.164 \\
\hline J ECON SURV & 114 & 124 & 0.654 & 0.986 & 1.975 & 0.00365 & 1.292 \\
\hline REV ENV ECON POLICY & 115 & 12 & 0.651 & 3.273 & 3.975 & 0.00366 & 2.587 \\
\hline INT LABOUR REV & 116 & 189 & 0.644 & 0.58 & 0.738 & 0.00089 & 0.475 \\
\hline FINANZARCHIV & 117 & 249 & 0.641 & 0.229 & 0.312 & 0.00038 & 0.2 \\
\hline J AFR ECON & 118 & 190 & 0.637 & 0.575 & 0.849 & 0.00163 & 0.541 \\
\hline J COMPET LAW ECON & 119 & 135 & 0.636 & 0.899 & 0.889 & 0.00151 & 0.565 \\
\hline STUD NONLINEAR DYN E & 120 & 199 & 0.635 & 0.511 & 0.939 & 0.0012 & 0.596 \\
\hline J PROD ANAL & 121 & 114 & 0.634 & 1.068 & 1.299 & 0.00255 & 0.824 \\
\hline J FORECASTING & 122 & 152 & 0.632 & 0.769 & 0.876 & 0.00188 & 0.554 \\
\hline ANNU REV RESOUR ECON & 123 & 129 & 0.626 & 0.949 & 1.426 & 0.00106 & 0.893 \\
\hline CEPAL REV & 124 & 244 & 0.620 & 0.259 & 0.25 & 0.00039 & 0.155 \\
\hline J MACROECON & 125 & 187 & 0.620 & 0.589 & 0.778 & 0.00289 & 0.482 \\
\hline
\end{tabular}




\begin{tabular}{|c|c|c|c|c|c|c|c|}
\hline Journal Title & ICQ Rank & 2YIF Rank & ICQ & 2YIF & 5YIF & Eigenfactor & AI \\
\hline JAHRB NATL STAT & 126 & 227 & 0.618 & 0.351 & 0.461 & 0.00089 & 0.285 \\
\hline J WORLD TRADE & 127 & 256 & 0.612 & 0.226 & 0.209 & 0.00051 & 0.128 \\
\hline J ACCOUNT ECON & 128 & 4 & 0.61 & 3.912 & 4.023 & 0.00741 & 2.453 \\
\hline GENEVA RISK INS REV & 129 & 166 & 0.602 & 0.722 & 0.732 & 0.00032 & 0.441 \\
\hline ECON SOC & 130 & 70 & 0.598 & 1.551 & 2.031 & 0.00278 & 1.214 \\
\hline REAL ESTATE ECON & 131 & 119 & 0.594 & 1.02 & 1.307 & 0.00172 & 0.777 \\
\hline ENERG J & 132 & 26 & 0.588 & 2.434 & 2.591 & 0.00527 & 1.524 \\
\hline AM J ECON SOCIOL & 133 & 223 & 0.584 & 0.389 & 0.365 & 0.00082 & 0.213 \\
\hline WORLD ECON & 134 & 141 & 0.583 & 0.872 & 1.244 & 0.00508 & 0.725 \\
\hline J REGUL ECON & 135 & 90 & 0.581 & 1.293 & 1.166 & 0.00172 & 0.677 \\
\hline INF ECON POLICY & 136 & 153 & 0.576 & 0.767 & 0.985 & 0.0013 & 0.567 \\
\hline J HEALTH ECON & 137 & 69 & 0.574 & 1.6 & 3.028 & 0.01309 & 1.739 \\
\hline ENVIRON RESOUR ECON & 138 & 56 & 0.573 & 1.795 & 2 & 0.0089 & 1.145 \\
\hline ECON EDUC REV & 139 & 125 & 0.568 & 0.981 & 1.527 & 0.00619 & 0.868 \\
\hline MANCH SCH & 140 & 210 & 0.561 & 0.454 & 0.515 & 0.00119 & 0.289 \\
\hline J APPL ECON & 141 & 207 & 0.561 & 0.469 & 0.41 & 0.00033 & 0.23 \\
\hline INT REV LAW ECON & 142 & 186 & 0.56 & 0.594 & 0.671 & 0.00104 & 0.376 \\
\hline RESOUR ENERGY ECON & 143 & 76 & 0.557 & 1.495 & 1.819 & 0.00294 & 1.013 \\
\hline CAMB J ECON & 144 & 128 & 0.553 & 0.951 & 1.477 & 0.00395 & 0.817 \\
\hline CONTEMP ECON POLICY & 145 & 175 & 0.551 & 0.671 & 0.673 & 0.00141 & 0.371 \\
\hline REV IND ORGAN & 146 & 142 & 0.551 & 0.87 & 0.878 & 0.00153 & 0.484 \\
\hline EMPIR ECON & 147 & 183 & 0.545 & 0.614 & 0.967 & 0.00305 & 0.527 \\
\hline ECON REC & 148 & 229 & 0.545 & 0.337 & 0.593 & 0.00121 & 0.323 \\
\hline ECON PHILOS & 149 & 191 & 0.544 & 0.565 & 0.935 & 0.00068 & 0.509 \\
\hline ECONOMIST-NETHERLAND & 150 & 150 & 0.541 & 0.795 & 1 & 0.00088 & 0.541 \\
\hline
\end{tabular}




\begin{tabular}{|c|c|c|c|c|c|c|c|}
\hline Journal Title & ICQ Rank & 2YIF Rank & ICQ & 2YIF & 5YIF & Eigenfactor & $\mathrm{AI}$ \\
\hline OXFORD REV ECON POL & 151 & 139 & 0.539 & 0.875 & 1.81 & 0.00278 & 0.976 \\
\hline LAND ECON & 152 & 93 & 0.535 & 1.261 & 1.507 & 0.00297 & 0.806 \\
\hline J DEV STUD & 153 & 140 & 0.531 & 0.872 & 1.08 & 0.00387 & 0.573 \\
\hline REV WORLD ECON & 154 & 144 & 0.529 & 0.829 & 1.102 & 0.0017 & 0.583 \\
\hline J AGR RESOUR ECON & 155 & 176 & 0.528 & 0.671 & 0.808 & 0.00116 & 0.427 \\
\hline ECON J WATCH & 156 & 104 & 0.528 & 1.147 & 0.973 & 0.00066 & 0.514 \\
\hline AM J AGR ECON & 157 & 123 & 0.528 & 0.99 & 1.507 & 0.00753 & 0.796 \\
\hline J ECON EDUC & 158 & 254 & 0.526 & 0.227 & 0.308 & 0.00049 & 0.162 \\
\hline REV INT POLIT ECON & 159 & 62 & 0.524 & 1.661 & 1.373 & 0.00222 & 0.719 \\
\hline ECON TRANSIT & 160 & 151 & 0.522 & 0.782 & 1.091 & 0.00142 & 0.57 \\
\hline REV INT ECON & 161 & 169 & 0.521 & 0.708 & 0.84 & 0.00258 & 0.438 \\
\hline IND CORP CHANGE & 162 & 87 & 0.519 & 1.331 & 2.197 & 0.00486 & 1.141 \\
\hline J REGIONAL SCI & 163 & 30 & 0.519 & 2.279 & 1.947 & 0.00335 & 1.011 \\
\hline AUST J AGR RESOUR EC & 164 & 82 & 0.519 & 1.415 & 1.691 & 0.00233 & 0.878 \\
\hline J ECON PSYCHOL & 165 & 111 & 0.519 & 1.081 & 1.749 & 0.00536 & 0.907 \\
\hline J CULT ECON & 166 & 34 & 0.518 & 2.222 & 1.945 & 0.00128 & 1.007 \\
\hline J ECON & 167 & 197 & 0.515 & 0.512 & 0.646 & 0.00113 & 0.333 \\
\hline SERIES-J SPAN ECON & 168 & 231 & 0.512 & 0.326 & 0.326 & 0.00013 & 0.167 \\
\hline WORLD DEV & 169 & 73 & 0.502 & 1.527 & 2.205 & 0.01433 & 1.107 \\
\hline JPN WORLD ECON & 170 & 218 & 0.5 & 0.414 & 0.506 & 0.00068 & 0.253 \\
\hline AUST ECON PAP & 171 & 262 & 0.5 & 0.171 & 0.358 & 0.00034 & 0.179 \\
\hline NEW POLIT ECON & 172 & 49 & 0.5 & 1.93 & 1.493 & 0.0018 & 0.746 \\
\hline INSUR MATH ECON & 173 & 109 & 0.499 & 1.095 & 1.37 & 0.00629 & 0.683 \\
\hline J HOUS ECON & 174 & 165 & 0.498 & 0.723 & 1.292 & 0.00127 & 0.644 \\
\hline J TRANSP ECON POLICY & 175 & 143 & 0.492 & 0.86 & 1.462 & 0.00133 & 0.719 \\
\hline
\end{tabular}




\begin{tabular}{|c|c|c|c|c|c|c|c|}
\hline Journal Title & ICQ Rank & 2YIF Rank & ICQ & 2YIF & 5YIF & Eigenfactor & $\mathrm{AI}$ \\
\hline J MEDIA ECON & 176 & 247 & 0.484 & 0.24 & 0.5 & 0.00024 & 0.242 \\
\hline INT FINANC & 177 & 185 & 0.482 & 0.6 & 0.927 & 0.00064 & 0.447 \\
\hline B INDONES ECON STUD & 178 & 85 & 0.479 & 1.333 & 1.053 & 0.00066 & 0.504 \\
\hline J REAL ESTATE RES & 179 & 132 & 0.478 & 0.925 & 1.069 & 0.0009 & 0.511 \\
\hline EUROPE-ASIA STUD & 180 & 208 & 0.477 & 0.464 & 0.692 & 0.00199 & 0.33 \\
\hline HEALTH ECON & 181 & 33 & 0.477 & 2.232 & 2.786 & 0.01157 & 1.328 \\
\hline AUST ECON REV & 182 & 235 & 0.475 & 0.3 & 0.276 & 0.00046 & 0.131 \\
\hline DEFENCE PEACE ECON & 183 & 195 & 0.473 & 0.551 & 0.696 & 0.00098 & 0.329 \\
\hline FEM ECON & 184 & 136 & 0.472 & 0.896 & 1.267 & 0.00121 & 0.598 \\
\hline JCMS-J COMMON MARK S & 185 & 67 & 0.468 & 1.603 & 1.624 & 0.00396 & 0.76 \\
\hline AUST ECON HIST REV & 186 & 226 & 0.464 & 0.355 & 0.414 & 0.00023 & 0.192 \\
\hline J RISK INSUR & 187 & 96 & 0.463 & 1.237 & 1.39 & 0.00225 & 0.643 \\
\hline J BANK FINANC & 188 & 91 & 0.463 & 1.287 & 1.721 & 0.01566 & 0.796 \\
\hline ECON HUM BIOL & 189 & 55 & 0.459 & 1.797 & 2.511 & 0.00366 & 1.152 \\
\hline REV ECON POLIT & 190 & 272 & 0.458 & 0.057 & 0.153 & 0.00021 & 0.07 \\
\hline ASIAN ECON J & 191 & 257 & 0.454 & 0.211 & 0.381 & 0.00029 & 0.173 \\
\hline J AGRAR CHANGE & 192 & 36 & 0.453 & 2.191 & 2.01 & 0.00167 & 0.91 \\
\hline APPL ECON PERSPECT P & 193 & 65 & 0.453 & 1.621 & 1.655 & 0.00076 & 0.749 \\
\hline AGR ECON-BLACKWELL & 194 & 118 & 0.451 & 1.03 & 1.349 & 0.00384 & 0.609 \\
\hline REV DEV ECON & 195 & 196 & 0.451 & 0.548 & 0.638 & 0.00135 & 0.288 \\
\hline HACIENDA PUBLICA ESP & 196 & 228 & 0.451 & 0.35 & 0.43 & 0.00034 & 0.194 \\
\hline J INT TRADE ECON DEV & 197 & 250 & 0.449 & 0.228 & 0.385 & 0.00041 & 0.173 \\
\hline J EVOL ECON & 198 & 164 & 0.448 & 0.723 & 1.23 & 0.00146 & 0.551 \\
\hline KYKLOS & 199 & 149 & 0.448 & 0.797 & 1.217 & 0.00149 & 0.545 \\
\hline EUR REV AGRIC ECON & 200 & 54 & 0.448 & 1.854 & 2 & 0.0018 & 0.895 \\
\hline
\end{tabular}




\begin{tabular}{|c|c|c|c|c|c|c|c|}
\hline Journal Title & ICQ Rank & 2YIF Rank & ICQ & 2YIF & 5YIF & Eigenfactor & $\mathrm{AI}$ \\
\hline J REAL ESTATE FINANC & 201 & 181 & 0.446 & 0.621 & 1.203 & 0.00217 & 0.536 \\
\hline PAC ECON BULL & 202 & 245 & 0.445 & 0.256 & 0.263 & 0.00024 & 0.117 \\
\hline CAMB J REG ECON SOC & 203 & 59 & 0.44 & 1.764 & 1.941 & 0.00152 & 0.855 \\
\hline OPEN ECON REV & 204 & 220 & 0.432 & 0.404 & 0.537 & 0.00076 & 0.232 \\
\hline S AFR J ECON & 205 & 234 & 0.43 & 0.315 & 0.328 & 0.00049 & 0.141 \\
\hline REV ECON APL-SPAIN & 206 & 264 & 0.429 & 0.158 & 0.17 & 0.00012 & 0.073 \\
\hline APPL ECON LETT & 207 & 236 & 0.427 & 0.295 & 0.302 & 0.00322 & 0.129 \\
\hline MAR RESOUR ECON & 208 & 94 & 0.427 & 1.261 & 1.411 & 0.00136 & 0.602 \\
\hline CHINA WORLD ECON & 209 & 206 & 0.423 & 0.476 & 0.591 & 0.00094 & 0.25 \\
\hline TRANSPORT RES B-METH & 210 & 16 & 0.422 & 2.944 & 3.52 & 0.00953 & 1.487 \\
\hline J AGR ECON & 211 & 75 & 0.422 & 1.5 & 1.679 & 0.00204 & 0.709 \\
\hline ANN REGIONAL SCI & 212 & 134 & 0.415 & 0.901 & 1.155 & 0.00237 & 0.479 \\
\hline CHINA ECON REV & 213 & 83 & 0.413 & 1.39 & 1.727 & 0.00306 & 0.714 \\
\hline CAN J AGR ECON & 214 & 163 & 0.41 & 0.724 & 0.808 & 0.0009 & 0.331 \\
\hline HITOTSUB J ECON & 215 & 273 & 0.407 & 0.048 & 0.167 & 0.00007 & 0.068 \\
\hline INDEP REV & 216 & 243 & 0.407 & 0.273 & 0.391 & 0.00036 & 0.159 \\
\hline PAP REG SCI & 217 & 71 & 0.396 & 1.541 & 1.731 & 0.00223 & 0.686 \\
\hline ECON MODEL & 218 & 193 & 0.396 & 0.557 & 0.699 & 0.00373 & 0.277 \\
\hline J ECON GEOGR & 219 & 23 & 0.394 & 2.6 & 3.955 & 0.00485 & 1.56 \\
\hline TRANSPORT RES E-LOG & 220 & 31 & 0.39 & 2.272 & 2.764 & 0.00692 & 1.077 \\
\hline TIJDSCHR ECON SOC GE & 221 & 159 & 0.388 & 0.753 & 1.236 & 0.00188 & 0.479 \\
\hline INT J TRANSP ECON & 222 & 222 & 0.387 & 0.393 & 0.333 & 0.00019 & 0.129 \\
\hline APPL ECON & 223 & 213 & 0.385 & 0.437 & 0.655 & 0.00634 & 0.252 \\
\hline FOOD POLICY & 224 & 35 & 0.384 & 2.212 & 2.78 & 0.0061 & 1.067 \\
\hline EASTERN EUR ECON & 225 & 258 & 0.379 & 0.211 & 0.38 & 0.00034 & 0.144 \\
\hline
\end{tabular}




\begin{tabular}{|c|c|c|c|c|c|c|c|}
\hline Journal Title & ICQ Rank & 2YIF Rank & ICQ & 2YIF & 5YIF & Eigenfactor & $\mathrm{AI}$ \\
\hline DEV ECON & 226 & 215 & 0.378 & 0.424 & 0.519 & 0.00028 & 0.196 \\
\hline J SPORT ECON & 227 & 160 & 0.371 & 0.743 & 0.896 & 0.00106 & 0.332 \\
\hline WORK EMPLOY SOC & 228 & 95 & 0.37 & 1.255 & 1.965 & 0.00257 & 0.727 \\
\hline ASIAN-PAC ECON LIT & 229 & 230 & 0.366 & 0.333 & 0.306 & 0.00012 & 0.112 \\
\hline ECON DEV Q & 230 & 182 & 0.366 & 0.618 & 0.938 & 0.00077 & 0.343 \\
\hline TRANSPORT RES A-POL & 231 & 21 & 0.361 & 2.725 & 3 & 0.00699 & 1.084 \\
\hline POST-SOV AFF & 232 & 89 & 0.361 & 1.31 & 1.014 & 0.00047 & 0.366 \\
\hline REG STUD & 233 & 79 & 0.36 & 1.465 & 2.165 & 0.00577 & 0.779 \\
\hline ESTUD ECONOMIA & 234 & 265 & 0.354 & 0.154 & 0.158 & 0.00006 & 0.056 \\
\hline SMALL BUS ECON & 235 & 105 & 0.353 & 1.13 & 2.228 & 0.00374 & 0.787 \\
\hline J ASIA PAC ECON & 236 & 263 & 0.353 & 0.159 & 0.306 & 0.00027 & 0.108 \\
\hline ECON GEOGR & 237 & 11 & 0.346 & 3.389 & 4.897 & 0.00258 & 1.696 \\
\hline VALUE HEALTH & 238 & 37 & 0.343 & 2.191 & 2.903 & 0.01259 & 0.997 \\
\hline EUR J HEALTH ECON & 239 & 39 & 0.343 & 2.095 & 1.976 & 0.00291 & 0.678 \\
\hline J AUST POLIT ECON & 240 & 219 & 0.342 & 0.412 & 0.313 & 0.00016 & 0.107 \\
\hline ENERG ECON & 241 & 24 & 0.34 & 2.538 & 3.291 & 0.01309 & 1.12 \\
\hline J FOREST ECON & 242 & 99 & 0.338 & 1.204 & 1.389 & 0.00078 & 0.469 \\
\hline J POST KEYNESIAN EC & 243 & 248 & 0.337 & 0.234 & 0.41 & 0.0004 & 0.138 \\
\hline ECOL ECON & 244 & 19 & 0.336 & 2.855 & 3.732 & 0.0295 & 1.255 \\
\hline J ECON POLICY REFORM & 245 & 198 & 0.335 & 0.511 & 0.462 & 0.00032 & 0.155 \\
\hline TRIMEST ECON & 246 & 260 & 0.333 & 0.175 & 0.108 & 0.00011 & 0.036 \\
\hline POST-COMMUNIST ECON & 247 & 202 & 0.332 & 0.492 & 0.503 & 0.00043 & 0.167 \\
\hline J ECON ISSUES & 248 & 224 & 0.33 & 0.376 & 0.379 & 0.00071 & 0.125 \\
\hline PHARMACOECONOMICS & 249 & 17 & 0.328 & 2.861 & 3.543 & 0.00747 & 1.162 \\
\hline AGRIBUSINESS & 250 & 156 & 0.315 & 0.763 & 0.806 & 0.00069 & 0.254 \\
\hline
\end{tabular}




\begin{tabular}{|c|c|c|c|c|c|c|c|}
\hline Journal Title & ICQ Rank & 2YIF Rank & ICQ & $2 \mathrm{YIF}$ & $5 Y I F$ & Eigenfactor & AI \\
\hline TRANSPORT POLICY & 251 & 72 & 0.315 & 1.541 & 2.161 & 0.00318 & 0.681 \\
\hline J TRANSP GEOGR & 252 & 47 & 0.294 & 1.942 & 2.52 & 0.00448 & 0.742 \\
\hline J POLICY MODEL & 253 & 161 & 0.291 & 0.737 & 1.082 & 0.00181 & 0.315 \\
\hline J CONSUM AFF & 254 & 116 & 0.285 & 1.047 & 1.481 & 0.00096 & 0.422 \\
\hline INVEST ECON-MEX & 255 & 270 & 0.274 & 0.079 & 0.084 & 0.00004 & 0.023 \\
\hline ACTA OECON & 256 & 241 & 0.268 & 0.273 & 0.28 & 0.0001 & 0.075 \\
\hline REV ECON MUND & 257 & 251 & 0.264 & 0.228 & 0.178 & 0.00013 & 0.047 \\
\hline FUTURES & 258 & 106 & 0.253 & 1.111 & 1.054 & 0.00215 & 0.267 \\
\hline CHINA AGR ECON REV & 259 & 205 & 0.238 & 0.476 & 0.462 & 0.00018 & 0.11 \\
\hline S AFR J ECON MANAG S & 260 & 269 & 0.222 & 0.113 & 0.135 & 0.00009 & 0.03 \\
\hline BALT J ECON & 261 & 267 & 0.182 & 0.143 & 0.077 & 0.00001 & 0.014 \\
\hline TECHNOL ECON DEV ECO & 262 & 14 & 0.180 & 3.224 & 1.972 & 0.00131 & 0.355 \\
\hline ECON COMPUT ECON CYB & 263 & 240 & 0.173 & 0.274 & 0.168 & 0.00012 & 0.029 \\
\hline EKON CAS & 264 & 259 & 0.172 & 0.194 & 0.232 & 0.0002 & 0.04 \\
\hline J KOREA TRADE & 265 & 274 & 0.171 & 0.033 & 0.076 & 0.00002 & 0.013 \\
\hline POLIT EKON & 266 & 168 & 0.171 & 0.722 & 0.556 & 0.00033 & 0.095 \\
\hline EKON ISTRAZ & 267 & 242 & 0.165 & 0.273 & 0.176 & 0.0001 & 0.029 \\
\hline J BUS ECON MANAG & 268 & 52 & 0.151 & 1.881 & 1.558 & 0.00068 & 0.236 \\
\hline ECON POLIT-ITALY & 269 & 233 & 0.133 & 0.318 & 0.225 & 0.00005 & 0.03 \\
\hline REV CIENC SOC-VENEZ & 270 & 276 & 0.129 & 0.01 & 0.031 & 0.00002 & 0.004 \\
\hline TRANSFORM BUS ECON & 271 & 209 & 0.127 & 0.459 & 0.513 & 0.0003 & 0.065 \\
\hline ZB RAD EKON FAK RIJE & 272 & 261 & 0.124 & 0.172 & 0.314 & 0.00005 & 0.039 \\
\hline INZ EKON & 273 & 127 & 0.12 & 0.972 & 0.828 & 0.00047 & 0.099 \\
\hline ROM J ECON FORECAST & 274 & 221 & 0.11 & 0.394 & 0.335 & 0.00017 & 0.037 \\
\hline EMERG MARK FINANC TR & 275 & 102 & 0.07 & 1.19 & 1.213 & 0.00033 & 0.085 \\
\hline REV ETUD COMP EST-O & 276 & 271 & 0.058 & 0.074 & 0.103 & 0.00001 & 0.006 \\
\hline
\end{tabular}




\begin{tabular}{l|c|c|c|c|c|c|c}
\hline Journal Title & ICQ Rank & 2YIF Rank & ICQ & 2YIF & 5YIF & Eigenfactor & AI \\
\hline Mean & & & 0.679 & 1.151 & 1.506 & 0.006 & 1.236 \\
Standard Deviation & & 0.37 & 0.959 & 1.353 & 0.011 \\
Maximum & & 1.772 & 6.667 & 10.16 & 1.771 \\
Minimum & & 0.058 & 0.01 & 0.031 & 0.1 & 12.205 \\
\hline
\end{tabular}

Notes: The top 276 Economics journals for which there are data on 5YIF and AI are ranked according to ICQ. The journal acronyms are taken from ISI. The data were downloaded from ISI on 21 February 2014. 
Table 2. Top 10 Econometrics Journals Ranked by ICQ

\begin{tabular}{|c|c|c|c|c|c|c|c|c|}
\hline Journal Title & $\begin{array}{c}\text { ICQ Rank } \\
\text { (Econometrics) }\end{array}$ & $\begin{array}{c}\text { ICQ Rank } \\
\text { (Economics) }\end{array}$ & 2YIF Rank & $\mathrm{ICQ}$ & $2 \mathrm{YIF}$ & $5 Y I F$ & Eigenfactor & AI \\
\hline ECONOMETRICA & 1 & 4 & 5 & 1.687 & 3.823 & 5.702 & 0.04571 & 9.622 \\
\hline ECONOMET THEOR & 2 & 5 & 77 & 1.683 & 1.477 & 1.473 & 0.01273 & 2.479 \\
\hline ECONOMET J & 3 & 19 & 120 & 1.372 & 1 & 1.252 & 0.00417 & 1.718 \\
\hline ECONOMET REV & 4 & 24 & 147 & 1.316 & 0.811 & 1.321 & 0.00425 & 1.738 \\
\hline J BUS ECON STAT & 5 & 27 & 48 & 1.254 & 1.932 & 2.369 & 0.01027 & 2.97 \\
\hline J ECONOMETRICS & 6 & 32 & 61 & 1.199 & 1.71 & 2.713 & 0.04063 & 3.254 \\
\hline REV ECON STAT & 7 & 36 & 28 & 1.153 & 2.346 & 3.669 & 0.02639 & 4.232 \\
\hline J FINANC ECONOMET & 8 & 39 & 126 & 1.091 & 0.976 & 1.58 & 0.00301 & 1.724 \\
\hline J APPL ECONOMET & 9 & 63 & 53 & 0.934 & 1.867 & 2.521 & 0.00995 & 2.355 \\
\hline OXFORD B ECON STAT & 10 & 73 & 170 & 0.862 & 0.707 & 1.767 & 0.00503 & 1.523 \\
\hline Mean & & & & 1.255 & 1.665 & 2.437 & 0.016 & 3.162 \\
\hline Standard Deviation & & & & 0.262 & 0.885 & 1.305 & 0.015 & 2.3 \\
\hline Maximum & & & & 1.687 & 3.823 & 5.702 & 0.046 & 9.622 \\
\hline Minimum & & & & 0.862 & 0.707 & 1.252 & 0.003 & 1.523 \\
\hline
\end{tabular}

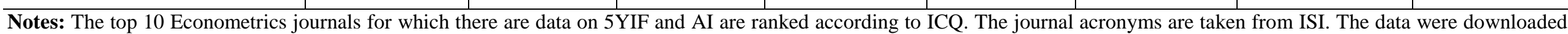
from ISI on 21 February 2014. 
Table 3

Correlation of 2YIF Ranks and ICQ Rank

for Top 276 Economics Journals

\begin{tabular}{|c|c|c|}
\hline & 2YIF Rank & ICQ Rank \\
\hline 2YIF Rank & 1 & \\
ICQ Rank & 0.302 & 1 \\
\hline
\end{tabular}

Table 4

Correlations of 5 RAMs

for Top 276 Economics Journals

\begin{tabular}{|c|c|c|c|c|c|}
\hline & 2YIF & 5YIF & Eigenfactor & AI & ICQ \\
\hline 2YIF & 1 & & & & \\
5YIF & 0.952 & 1 & & & \\
Eigenfactor & 0.578 & 0.651 & 1 & & \\
AI & 0.808 & 0.883 & 0.725 & 1 & \\
ICQ & 0.373 & 0.426 & 0.487 & 0.676 & 1 \\
\hline
\end{tabular}


Table 5

Correlation of 2YIF Rank and ICQ Rank for Top 10 Econometrics Journals

\begin{tabular}{|c|c|c|}
\hline & 2YIF Rank & ICQ Rank \\
\hline 2YIF Rank & 1 & \\
ICQ Rank & 0.338 & 1 \\
\hline
\end{tabular}

Table 6

\section{Correlations of 5 RAMs}

for Top 10 Econometrics Journals

\begin{tabular}{|c|c|c|c|c|c|}
\hline & 2YIF & 5YIF & Eigenfactor & AI & ICQ \\
\hline 2YIF & 1 & & & & \\
5YIF & 0.957 & 1 & & & \\
Eigenfactor & 0.811 & 0.845 & 1 & & \\
AI & 0.949 & 0.955 & 0.824 & 1 & \\
ICQ & 0.464 & 0.301 & 0.391 & 0.543 & 1 \\
\hline
\end{tabular}

